\title{
MicroRNA-Mediated Host-Pathogen Interactions Between Bombyx mori and Viruses
}

\author{
Mian Muhammad Awais ${ }^{1}$, Muhammad Shakeel ${ }^{2}$ and Jingchen Sun ${ }^{1 *}$ \\ 'Guangdong Provincial Key Laboratory of Agro-animal Genomics and Molecular Breeding and Sub-Tropical Sericulture and \\ Mulberry Resources Protection and Safety Engineering Research Center, College of Animal Science, South China \\ Agricultural University, Guangzhou, China, 'Laboratory of Bio-Pesticide Innovation and Application of Guandong Province, \\ College of Plant Protection, South China Agricultural University, Guangzhou, China
}

OPEN ACCESS

Edited by: Senthil-Nathan Sengottayan, Manonmaniam Sundaranar University, India

Reviewed by:

Fanchi Li,

Soochow University, China Dulce Santos, KU Leuven, Belgium

*Correspondence: Jingchen Sun

cyfz@scau.edu.cn

Specialty section: This article was submitted to Invertebrate Physiology, a section of the journal

Frontiers in Physiology

Received: 25 February 2021 Accepted: 14 April 2021 Published: 07 May 2021

Citation:

Awais MM, Shakeel M and Sun J (2021) MicroRNA-Mediated Host-Pathogen Interactions Between Bombyx mori and Viruses.

Front. Physiol. 12:672205.

doi: 10.3389/fphys.2021.672205
MicroRNAs (miRNAs), small non-coding RNAs of about 22 nucleotides, have been reported to regulate gene expression at the posttranscriptional level and are involved in several biological processes such as immunity, development, metabolism, and hostpathogen interactions. Apart from miRNAs encoded by the host, miRNAs produced by pathogens also regulate host genes to facilitate virus replication and evasion of the host defense responses. In recent years, accumulated studies suggest that viral infections alter the host miRNAs expression profile, and both cellular and viral miRNAs may play vital roles in host-pathogen interactions. Bombyx mori, one of the critical lepidopteran model species, is an economically important insect for silk production. The mechanism of interaction between $B$. mori and its pathogens and their regulation by miRNAs has been extensively studied. Therefore, in this review, we aim to highlight the recent information and understanding of the virus-encoding miRNAs and their functions in modulating viral and host (B. mori) genes. Additionally, the response of $B$. mori derived miRNAs to viral infection is also discussed. A detailed critical view about miRNAs' regulatory roles in B. mori-virus interactions will help us understand molecular networks and develop a sustainable antiviral strategy.

Keywords: miRNA, BmNPV, Bombyx mori, host-pathogen interaction, viruses

\section{INTRODUCTION}

The understanding of gene expression guided by regulatory RNA molecules is not limited to the past 20 years. According to Britton and Davidson, genes might be turned on and off by activator RNA molecules based on Watson-Crick base pairing to the sites located within genes. Later, the idea was abandoned with the discovery of transcription factors (Britten and Davidson, 1969). As per our understanding, it is now clear that RNAs, especially the small RNAs (sRNA), actually regulate gene expression.

MicroRNA (MiRNA), small interfering RNAs (siRNA), and piwi-interacting RNAs (piRNA) are the three main classes of sRNAs that regulate gene expression (Farazi et al., 2008; Moazed, 2009; Czech and Hannon, 2011). These three classes are based on size and interaction with a particular protein class called the argonaute (Ago) protein family (Kim, 2008). MiRNAs are endogenous $22 \mathrm{nt}$ RNAs that have an interaction with Ago-1 protein in insects 
(Kawamata et al., 2009; Miyoshi et al., 2009; Okamura et al., 2009; Ghildiyal et al., 2010). siRNA with a length of $20 \mathrm{nt}$ (Zografidis et al., 2015; Santos et al., 2019) interacts with Ago-2 (Czech et al., 2009) and piRNAs of 24-31 nt with the Piwi-subfamily of Ago proteins (Siomi et al., 2011).

Two transcripts, the $22 \mathrm{nt}$ lin-4 s (small) and the $61 \mathrm{nt}$ lin-4 L (large) originating from the lin-4 locus, led to the discovery of the first miRNA in Caenorhabditis elegans (Lee et al., 1993; Wightman et al., 1993). These small transcripts were found to contain sequences complementary to the 3' untranslated region (UTR) of lin-14 mRNA, indicating that these transcripts regulate the lin-14 translation via some unique antisense mechanism. In 2000, after 7 years of the first miRNA discovery, the next miRNA was discovered in C. elegans, indicating that the $21 \mathrm{nt}$ let-7 temporally regulates lin-41 by binding to the target sites within its $3^{\prime}$ UTR (Reinhart et al., 2000).

The discovery of lin-4 and let-7 added a new dimension to our understanding of complex gene regulatory networks, and since their discovery, thousands of putative miRNAs have been identified in various organisms. MiRNAs encoded by host cells or by a viral genome are involved in the interaction between the host and the pathogen, opening new research windows in insect microbe interaction. In this review article, miRNA's role in insect host-pathogen crosstalk, especially in Bombyx mori, with examples from viruses and the host with the availability of the most recent literature, will be discussed.

\section{miRNA BIOGENESIS}

Several processing steps are involved in miRNA biogenesis, including transcription of the miRNA, loading and assembly into the RNA-induced silencing complex (RISC), and miRNA maturation. As most of the short RNAs are transcribed by polymerase III (RNA pol III), it was thought that the transcriptions of the majority of miRNAs loci are also mediated by the RNA pol III. It is also suggested that RNA pol III may mediate the transcription of miRNAs positioned within repetitive sequences (Borchert et al., 2006). On the other hand, the structure of genes encoding the miRNAs and direct experimental results indicate that RNA pol II is the primary RNA polymerase that initiates the transcription of miRNAs loci in animals. In several primary miRNA transcripts, the presence of traditional 5' 7-methyl guanosine caps and 3' polyadenylation and their sensitivity to $\alpha$-amanitin having inhabiting interaction with RNA pol II suggest the class-II nature of genes having miRNA loci (Lee et al., 2004; Figure 1). All these results confirmed that RNA Poll II is involved in the transcription of miRNAs.

\section{The Microprocessor Complex Fine-Tunes the pri-miRNA}

The initial product of RNA Poll II transcriptions is primary miRNA (pri-miRNA) transcripts. These pri-miRNAs have one or more hairpin loop structures, and their length ranges into several hundred kilobases. The microprocessor complex processes these long

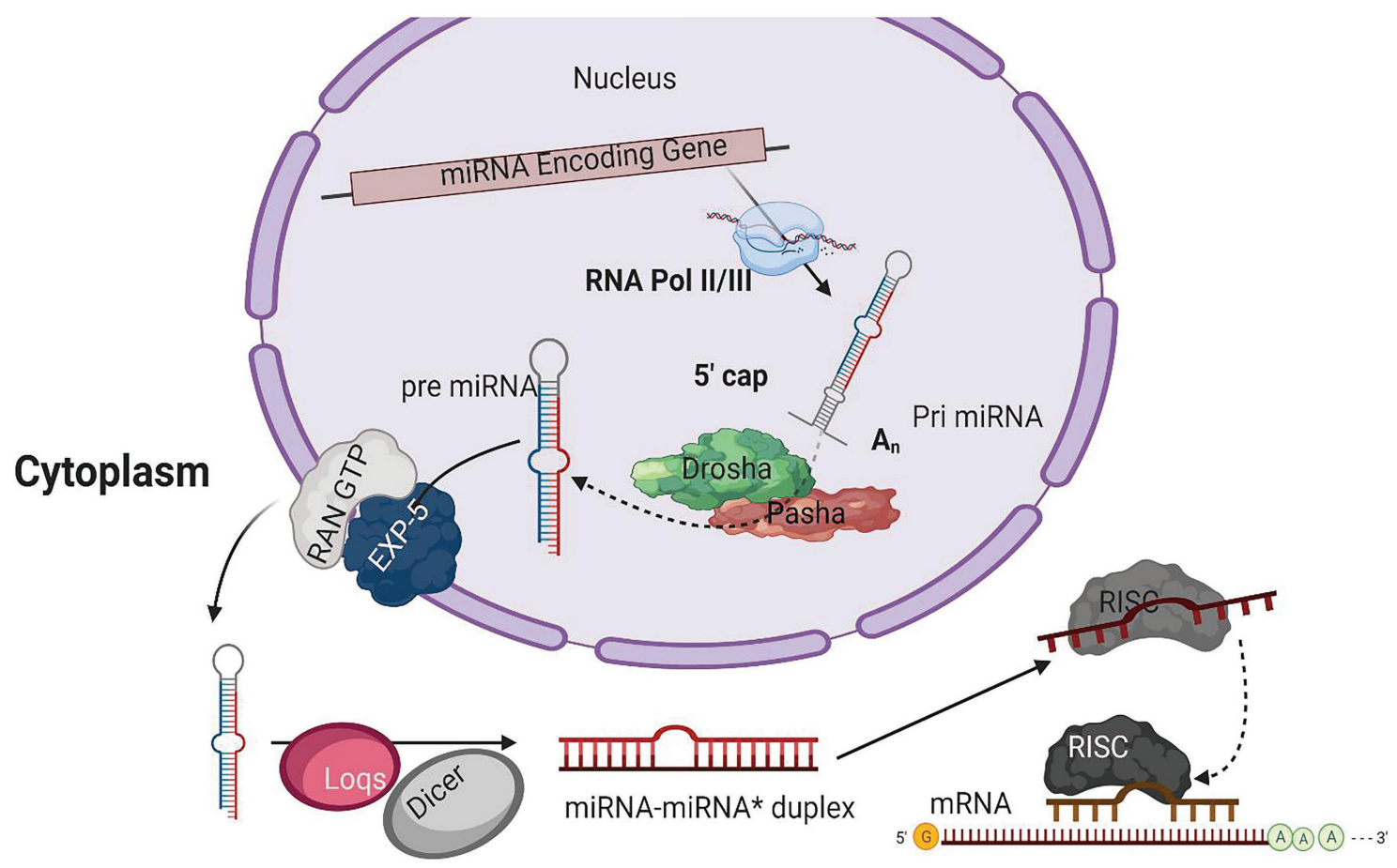

FIGURE 1 | A typical model for miRNA biogenesis. RNA polymerase II(RNA pol II), transcribing miRNA gene into a hair-loop structure known as the pri-miRNA. The Drosha/Pasha microprocessor complex process pri-miRNA to pre-miRNA in the nucleus. The pre-miRNA is exported into the cytoplasm in a RanGTP/Exp-5 dependent manner. The pre-miRNA is processed by Dicer-1 (Dcr-1) and Loquacious (Loqs) to form the miRNA-miRNA* duplex within the cytoplasm. The duplex strands are then sorted, and the miRNA strand is loaded into the RISC complex that typically includes Argonaut 1 (Ago-1). 
transcripts (pri-miRNAs) into $70 \mathrm{nt}$ precursor miRNAs (pre-miRNA) in the nucleus (Conrad et al., 2014). Drosha, an RNase III enzyme along with its double-stranded RNA (dsRNA) binding partner, Pasha, constitutes the microprocessor complex (Lee et al., 2003; Denli et al., 2004; Gregory et al., 2004; Han, 2004; Landthaler et al., 2004; Kawai and Amano, 2012; Burke et al., 2014; Nguyen et al., 2015; Kim et al., 2016a). The stem structure of pri-miRNA with $30 \mathrm{bp}$ has a terminal loop, and flanking segments are processed by the microprocessor complex after recognition. The dsRNA binding partner protein Pasha recognizes substrate pri-miRNA, plays an important part in anchoring to the flanking single-stranded RNA (ssRNA) and dsRNA stem junction, and locating the position 11 bp into the stem, where Dorsha is loaded to cleave the pri-mRNA (Lee et al., 2003; Denli et al., 2004). For further processing, the end product of Drosha-Pasha processing, a $70 \mathrm{nt}$ pre-miRNA, is exported into the cytoplasm by Exportin-5 (Exp-5; Kim et al., 2016). The pre-miRNA generated by Drosha's action on pri-miRNA has a 2 nt $3^{\prime}$ overhang, critical for pre-miRNA export. Exp-5, a dsRNA-binding receptor depending on ran guanosine triphosphate (RanGTP), starts the nuclear export of pre-miRNAs by identifying the $2 \mathrm{nt} 3$ ' overhang structure of pre-miRNA in the nucleus (Bohnsack, 2004). The Exp-5/pre-miRNA complex migrates through the nuclear pore complexes into the cytoplasm. In the cytoplasm, RanGTP is hydrolyzed to RanGDP, which results in the release of pre-miRNA from the Exp-5/ pre-miRNA complex. The pre-miRNAs are protected from digestion by nucleases of Exp-5, which is also the nuclear export factor of pre-miRNAs (Yi, 2003; Lund, 2004).

\section{Pre-miRNA Processing by Dicer}

An RNase III enzyme, Dicer-1 (Dcr-1), slices the terminal loop structure of pre-miRNA, releasing a $\sim 22$ nt miRNAmiRNA* duplex in the cytoplasm (Hutvagner, 2001; Koscianska et al., 2011; Feng et al., 2012; Gurtan et al., 2012; Bogerd et al., 2014). Dicer, a core enzyme in the RNAi pathway, was first identified in Drosophila (Bernstein et al., 2001). Two Dicer enzymes, Dcr-1 and Dcr-2, are encoded by the $B$. mori genome having the specialized function in two crucial pathways, i.e., miRNA and siRNA pathways (Ponnuvel et al., 2007; Kolliopoulou and Swevers, 2013). A pre-miRNA processing complex is formed by the interaction of Dcr-1 with Loquacious (Loqs) (Saito et al., 2005). The pre-miRNA is accumulated, and mature miRNAs are reduced when RNAi depletes the Loqs; depletion of Dcr-1 also results in similar effects (Jiang, 2005).

\section{miRNA Strand Selection and Argonaute Loading}

From mature miRNA-miRNA* duplex resulted from pre-miRNAs processing by Dcr-1, a strand from the duplex is loaded into the RISC. RNA-binding proteins guided by sRNA from the argonaute family are the fundamental components of the RISC. Four discrete ago proteins encoded by the $B$. mori genome are classified into two sub-clades: Ago and Piwi (Wang et al., 2013). Subgroup ago includes the ago-1 and ago-2 proteins that bind with miRNAs and siRNAs, respectively (Hammond, 2001). The mature miRNA guide strand is loaded into ago-1, while the miRNA* strand is degraded (Kawamata et al., 2009). The miRNA-Ago complex is ready to perform its action on target sequences.

\section{miRNAS MODULATING HOST-PATHOGEN INTERACTION}

The role of miRNAs in insect development has been studied extensively. A lot has also been studied in recent years related to miRNAs' functional role in infection establishment as these modulate the host-pathogen interactions. For instance, quite a few reports describe viral and cellular miRNAs' involvement in infection propagation by limiting viral replication (see below). The expression profile of a large number of miRNAs has been shown to alter upon the pathogen's invasion. The modulation of host and pathogens genes is also reported by the miRNAs encoded by the host and pathogens. Below, we will examine the manipulation of genes from different miRNAs sources, which intern mediate the host-pathogen interaction.

\section{Impact of Viral Infection on the Host miRNA Profile}

Several studies have reported change in cellular miRNAs expression levels in insects in response to pathogen infection based on deep sequencing or microarray analysis (Figure 2). For example, Karamipour investigated the difference in the expression profile of cellular miRNA-184 and let-7 following Autographa californica nucleopolyhedrovirus (AcMNPV) infection of Sf-9 cells. Findings suggested that following AcMNPV infection, there was a difference in the expression of cellular miRNAs at the post-infection times. The expression profile of the core components of miRNA's biogenesis pathway, Dcr1, Ago1, and Exp5, was upregulated at $16 \mathrm{~h}$ post-infection (hpi) following AcMNPV infection. Though, in response to virus infection, Ran's expression was decreased (Karamipour et al., 2019). An abundant miRNA, Bantam, accounts for more than $5 \%$ of the total miRNA of Sf9 cells. Sequenced data suggested that the bantam level was increased late in AcMNPV infection and confirmed with real-time quantitative PCR in infected Sf9 cells and Spodoptera litura larvae (Shi et al., 2016).

At $24 \mathrm{~h} \mathrm{pi}$, there was an increase of 2.5-fold in bantam level in uninfected cells, and a high level of bantam was also present late in the infection. The bantam level was also about 1.5-fold more elevated than the control in AcMNPV-infected $S$. litura larvae, indicating that bantam has a role in the growth and modulates the insect-baculovirus interaction as well (Shi et al., 2016).

Deep sequencing of Bombyx mori cytoplasmic polyhedrosis virus (BmCPV) infected midgut of silkworm suggests that the expression profile of host miRNAs were altered after 72 and $96 \mathrm{~h}$ of viral inoculation. In the RNA libraries constructed from the BmCPV-infected midgut of silkworm and the control midgut, a total of 316 known miRNAs (including miRNA*) and 90 novel miRNAs were identified. A significant difference in the expression of 58 miRNAs was observed between the infected and the normal midgut (Wu et al., 2013). Two small RNA libraries were constructed from Bombyx mori nuclear polyhedrosis virus (BmNPV) infected larvae and the control larvae. Solexa sequencing results revealed 


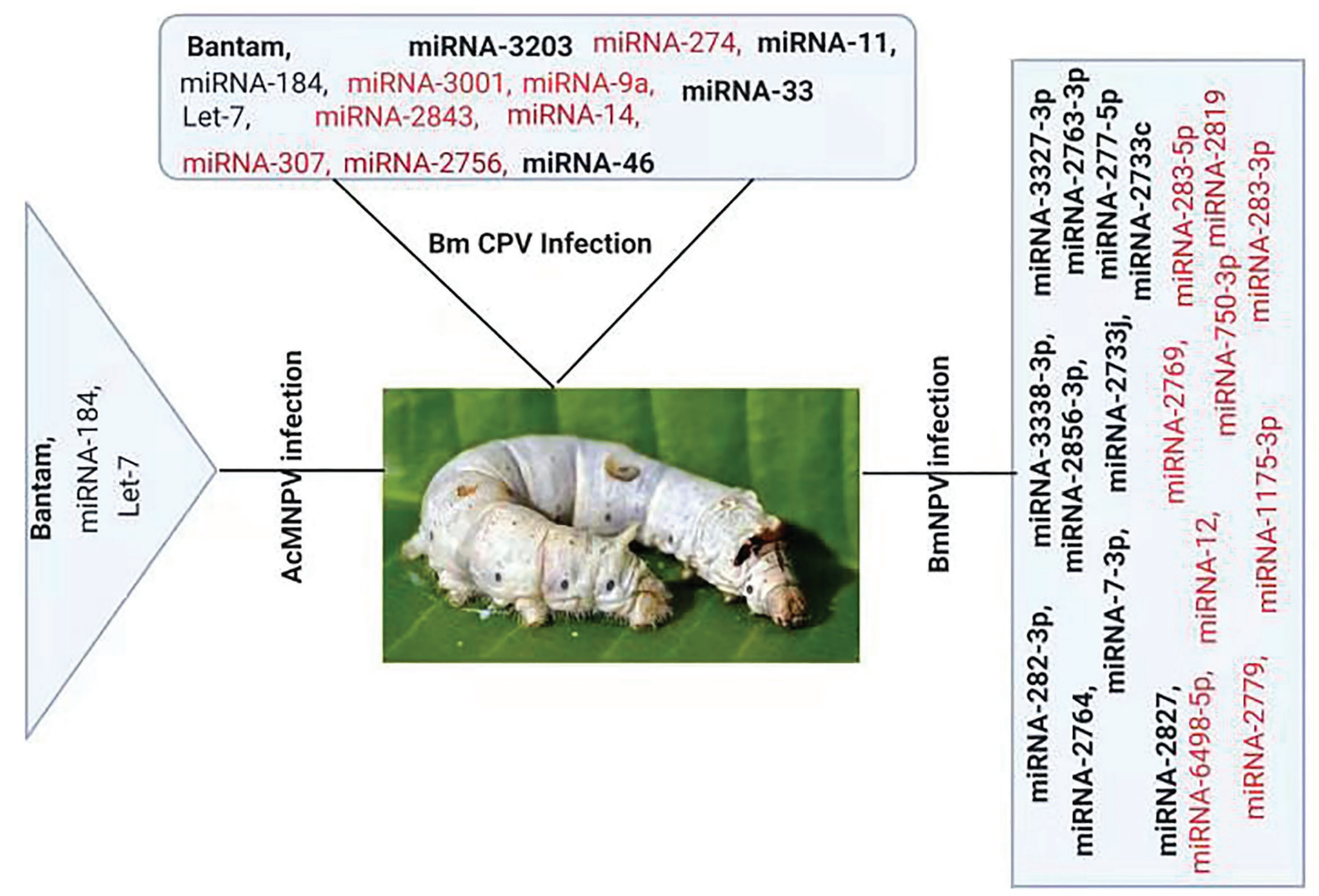

FIGURE 2 | Differential Expression of host miRNA upon viral invasion: Regulation of miRNAs upon BmNPV, BmCPV, and AcMNPV. Red color represents downregulated, while bold black represents up-regulated miRNAs after the viral attack.

significant downregulation of miR-2819 in infected larvae (Wu et al., 2019). Results showed that miR-2819 has a relatively high abundance in several tissues, including Malpighian tubules, fat body, hemolymph, silk gland, and midgut. The abundance of miR-2819 of infected cells was compared with that of control cells at different time points. The results showed that during the 6-12 hpi, the expression level of miR-2819 was increased, while during 24-72 hpi, the expression level of miR-2819 was significantly declined (Wu et al., 2019).

The knowledge about the modulation by miRNAs in the establishment of infection is increasing as more of these studies are emerging. New dimensions are now discovered how the complex phenomena of host-pathogens occurred upon pathogens invasion and how the host responds to these invading pathogens.

\section{Host miRNA's Impact on Viral Infection}

Cellular miRNAs may directly target viral genes and impact the propagation and establishment of infection (Table 1). Apart from regulating cellular processes, host miRNAs also have a crucial role in defense against pathogen attack, thus helping in infection propagation (Skalsky and Cullen, 2010; Asgari, 2011; Hussain and Asgari, 2014). miRNA also addresses the biotic stresses like protein-coding genes (Ghosh et al., 2009; Croston et al., 2018). A large number of miRNAs have a differential expression upon pathogen attack (Ghosh et al., 2009; Maudet et al., 2014; Croston et al., 2018). This differential
TABLE 1 | Host miRNAs targeting viral genes.

\begin{tabular}{|c|c|c|c|}
\hline $\begin{array}{l}\text { Host } \\
\text { miRNAs }\end{array}$ & $\begin{array}{l}\text { Functional target in the } \\
\text { viral genome }\end{array}$ & Function & References \\
\hline miR-8 & $\begin{array}{l}\text { BmNPV immediate-early } \\
\text { gene (ie-1) }\end{array}$ & Replication & Singh et al., 2012 \\
\hline bantam & lef8, gp41, and p10 & & Shi et al., 2016 \\
\hline miR-278-3p & $\begin{array}{l}\text { Insulin-related peptide- } \\
\text { binding protein } 2 \text { (IBP2) }\end{array}$ & $\begin{array}{l}\text { B.mori immune } \\
\text { response }\end{array}$ & Wu et al., 2016 \\
\hline miR-274-3p & $\begin{array}{l}\text { BmCPV nonstructural } \\
\text { protein } 5 \text { (NS5) and p10 }\end{array}$ & Viral replication & Wu et al., 2017 \\
\hline miR-2,819 & $\begin{array}{l}\text { BmNPV immediate-early } \\
\text { gene (ie-1) }\end{array}$ & Replication & Wu et al., 2019 \\
\hline miR-390 & BmNPV-cg30 & $\begin{array}{l}\text { Occlusion bodies } \\
\text { formation }\end{array}$ & Kang et al., 2018 \\
\hline
\end{tabular}

expression of miRNAs indicated the critical role they play in host-pathogen interactions. For instance, with various putative binding sites, B. mori miR- 8 was defined as an antiviral miRNA. The putative binding sites were on the BmNPV immediateearly gene (ie-1) mRNA and other vital genes of BmNPV. On blocking of Bmo-miR-8, a 3-fold increase in the ie-1 transcript level and an 8-fold increase in BmNPV accumulation in fat body tissues of infected larvae was observed, indicating a significant increase in the virus load in the infected $B$. mori larvae (Singh et al., 2012). Similarly, the role of bantam on viral infection was studied. The results indicated that cellular 
miRNA bantam in Sf9 cells plays an essential role in insect growth and baculovirus-insect interaction. The expression of the most affected viral genes lef8, gp41, and p10 was increased by 8,10 , and 40 times after applying bantam inhibitor or mimic in Sf9 cells. In infected Spodoptera exigua, larval mortality increased from $47 \%$ without antago-miR (bantam inhibitor) to $80 \%$ with it (Shi et al., 2016). In another study, it was demonstrated that miR-278-3p plays a vital role in BmCPV replication. Insulin-related peptide-binding protein 2 (IBP2) gene, induced by $\mathrm{BmCPV}$ infection, having a vital role in B. mori immune response, was identified as one of the targets of miR-278-3p by using a luciferase reporter assay. Overexpression of miR-278-3p negatively regulates the expression of IBP2 in silkworm larvae and positively regulates the mRNA transcript level of BmCPV, and confirms that the miR-278-3p is important for viral infection establishment (Wu et al., 2016). Bombyx mori miR-2,819 effectively downregulates the immediate early gene ie-1 required for viral replication, affecting the viral infection. miR-2,819 also affects other gene's expression, i.e., polyhedrin and VP39 of BmNPV (Wu et al., 2019).

Accumulation of 20-hydroxyecdysone (20E) in the late phase of larval instar results in the initiation of molting and metamorphosis (Riddiford et al., 2003). MiRNA bantam affects baculovirus-host interaction by regulating 20E. Reduction in bantam level results in an increased level of 20E, resulting in high mortality in virus-infected S. exigua (Ran et al., 2018). Bmo-miR-390 effectively downregulates the expression of BmNPV-cg30 in BmNPV-infected BmN cells. Cg30 gene of $\mathrm{BmNPV}$ is required to replicate $\mathrm{BmNPV}$ as a deletion or mutation in this gene results in decreased occlusion bodies (OB) production and reduction in toxicity to the silkworm larvae (Ishihara et al., 2013; Kang et al., 2018).

The impact of miR-274-3p on the BmCPV replication in the silkworm larvae infected with the BmCPV was investigated. The experimental techniques, including bioinformatics analysis, identified BmCPV Nonstructural protein 5 (NS5) as the potential target of miR-274-3p. qRT-PCR and Western blotting results revealed that the level of NS5 was reduced significantly by miR-274-3p inhibitors, while the polyhedrin gene expression was increased after the application of miR-274-3p inhibitors. The inhibition of miR-274-3p facilitates BmCPV replication by upregulating BmCPV NS5 gene expression (Wu et al., 2017). The authors demonstrated that mature artificial miRNAs (amiRNAs) expressed successfully target the viral lef-11 gene. Mature amiRNAs efficiently inhibited the BmNPV proliferation by silencing the target gene. The overexpression of mature amiRNAs may induce acute cellular toxicity (Zhang et al., 2014). Next-generation sequencing (NGS) showed that 167 genes were upregulated and 141 genes were downregulated in larval instars of $B$. mori following pathogenic infection. Several genes with a role in $B$. mori immune response against BmCPV were identified. The 2-fold upregulation of the core RNAi genes Ago-2 and Dcr-2 was observed during pathogenic infection (Kolliopoulou et al., 2015). Reports revealed that exo-RNAi is operative in the silkworm B. mori against pathogenic infection of BmCPV, which is characterized by a segmented dsRNA genome (Zografidis et al., 2015).

\section{Viral miRNA Can Target Viral Own Genes}

MicroRNAs carry out their functions through their targets, and for viral miRNAs, their targets can be the host genes or the viral genes. MiRNAs can bind to the 3' or 5' UTR of the target mRNA, and they also can bind to coding sequences to manipulate target gene expression (Table 2). For instance, bmnpv-miR-3 miRNA encoded by BmNPV modulates the expression of DNA binding protein (P6.9), vital for the late stage of viral infection in the host, $B$. mori. The downregulation of BmNPV late genes helps BmNPV escape the host's early immune response (Singh et al., 2014). The viral miRNAs are mainly involved in the active regulation of viral genes. It may reduce the viral DNA load and the number of infectious budded virions (BVs) to avoid host surveillance and prolong residence duration inside the host cell.

AcMNPV-miR-1 is an AcMNPV encoded miRNA. The ac-94 gene involved in producing infectious BVs was downregulated by AcMNPV-miR-1, resulting in the decreased production of BVs and enhancing the formation of occlusionderived virions (ODVs). The overexpression of AcMNPV-miR-1 reduces the budded virus's infectivity, affecting viral DNA replication and accelerating ODVs formation. AcMNPV-miR-1 moderately downregulated ac95 and upregulated ac18. These findings suggest that AcMNPV-miR-1 restrains virus infection of cells but facilitates virus infection of larvae (Zhu et al., 2016; Wang et al., 2020a). The most distinct downregulation for AcMNPV-miR-2 was observed for lef-6, with lef-11, orf-49, and orf-63 also showing apparent downregulation, while orf-38 did not exhibit significant regulation (Wang et al., 2020a). AcMNPV-miR-3 plays a regulatory role in BV and ODV production. AcMNPV-miR-3 is located on the opposite strand of the viral gene ac101 coding sequence in the AcMNPV genome and detected at $6 \mathrm{hpi}$. and reaches a maximum level of around $12 \mathrm{hpi}$. in AcMNPV-infected Sf9 cells. AcMNPV-miR-3 downregulates ac101 through a siRNA-like cleavage mode. Ac101 is a core gene required for BV and ODV production, viral infectivity, and virus-induced nuclear actin polymerization. Dual-luciferase reporter assay revealed a slight downregulation with ac23, ac25, ac86, and ac98 target sites (Jiao et al., 2019; Wang et al., 2020a).

TABLE 2 | Viral micro RNA can target viral own genes.

\begin{tabular}{|c|c|c|c|}
\hline Viral miRNA & Target genes & Function & References \\
\hline BmNPV-miR-3 & P6.9-gene & $\begin{array}{l}\text { Viral infection } \\
\text { establishment }\end{array}$ & Singh et al., 2014 \\
\hline AcMNPV-miR-1 & Ac-94-gene & Viral DNA replication & Zhu et al., 2016 \\
\hline AcMNPV-miR-3 & Ac101-gene & $\begin{array}{l}\text { BV and ODV } \\
\text { production }\end{array}$ & Jiao et al., 2019 \\
\hline AcMNPV-miR-1 & $\begin{array}{l}\text { Ac-95(down } \\
\text { regulation) \& Ac-18 } \\
\text { (up Regulation) }\end{array}$ & $\begin{array}{l}\text { DNA helicase, } \\
\text { replication related }\end{array}$ & Wang et al., 2020a \\
\hline AcMNPV-miR-2 & $\begin{array}{l}\text { lef- } 6 \text {, lef- } 11 \text {, } \\
\text { orf- } 49 \text {, and orf-63 }\end{array}$ & $\begin{array}{l}\text { DNA replication, late } \\
\text { gene transcription }\end{array}$ & Wang et al., 2020a \\
\hline AcMNPV-miR-3 & $\begin{array}{l}\text { Ac23, ac25, ac86, } \\
\text { and ac98 }\end{array}$ & $\begin{array}{l}\text { Polynucleotide inase/ } \\
\text { ligase and fusion protein }\end{array}$ & Wang et al., 2020a \\
\hline
\end{tabular}


The cellular state from susceptible to resistant or vice versa may be remodeled upon abnormal-expression of cellular miRNAs due to the abnormal expression of their target genes (Ghosh et al., 2009). A huge amount of literature is available describing miRNAs' identification from insect hosts, but the exact role in host-pathogen interactions is still limited to a few reports (Ylla et al., 2016; Kozomara et al., 2019). Moreover, these studies mainly focus on miRNA alterations due to the viral attack in insects (Tang et al., 2019).

\section{Viral miRNAs Exploit the Host Machinery}

Recent investigations have revealed that viral miRNAs might target and regulate host genes to establish infection and successfully replicate. However, the information is minimal concerning insect viruses. The miRNAs' impact might be via regulation of a specific gene leading to modifying a particular pathway or might cause a global reduction in the host miRNA depending on the target genes (Table 3). For instance, a BmNPV encoded miRNA (bmnpv-miR-1) has been shown to downregulate the host GTP-binding nuclear protein Ran's expression, thereby inhibiting small RNA transport from the nucleus into the cytoplasm to ensure their active proliferation (Singh et al., 2012). Reports indicated that an insect doublestranded RNA virus (BmCPV) might generate miRNAs, and these miRNAs play an essential role in host viral interaction. BmCPV-miR-3 and BmCPV-miR-5 regulate host target genes and manipulate viral replication and proliferation (Pan et al., 2017) AcMNPV encoded miRNA AcMNPV-miR-4 interfere with the host cell cycle, cytokine secretion, exocytosis, and membrane fusion as it targets the ALG2 and ROP genes. ALG-2 is involved in apoptosis initiation. Rop is highly expressed in the nervous system and in specialized tissues where intensive exocytic/endocytic cycles occur, providing evidence that it impacts viral infection and propagation (Jiao et al., 2019). A BmCPV-derived miRNA (BmCPV-miR-1) effectively up-regulates the expression of the $B$. mori inhibitor of apoptosis protein (BmIAP) gene. It inhibits cell apoptosis mechanisms, hence favoring better replication of the virus and helps in viral infection establishment (Guo et al., 2020).

E66 a structural protein of the ODV encoded by ORF37 of the BmNPV genome. It also encodes a miRNA BmNPV-miR-415, which produces bmo-miR-5738 when

TABLE 3 | Viral mRNAs exploit the host machinery.

\begin{tabular}{|c|c|c|c|}
\hline Viral mRNAs & $\begin{array}{c}\text { Targets gene in } \\
\text { host }\end{array}$ & Function & References \\
\hline BmNPV-miR-1 & $\begin{array}{l}\text { GTP-binding } \\
\text { nuclear protein Ran } \\
\text { encoding gene }\end{array}$ & $\begin{array}{l}\text { Inhibits transport from } \\
\text { nucleus to cytoplasm }\end{array}$ & Singh et al., 2012 \\
\hline $\begin{array}{l}\text { BmNPV- } \\
\text { miR-415 }\end{array}$ & TOR2 & $\begin{array}{l}\text { Metabolism and } \\
\text { development }\end{array}$ & Cao et al., 2017 \\
\hline BmCPV-miR-3 & $\begin{array}{l}\text { Purine nucleoside } \\
\text { phosphorylase } \\
\text { encoding gene }\end{array}$ & $\begin{array}{l}\text { Cell proliferation } \\
\text { inhibition }\end{array}$ & Pan et al., 2017 \\
\hline BmCPV-miR-1 & BmlAP gene & Inhibits cell apoptosis & Guo et al., 2020 \\
\hline AcMNPV-miR-4 & $\begin{array}{l}\text { ALG2 and ROP } \\
\text { genes }\end{array}$ & $\begin{array}{l}\text { Apoptosis initiation } \\
\text { blocked }\end{array}$ & Jiao et al., 2019 \\
\hline
\end{tabular}

introduced into the host cells. Bmo-miR-5738 upregulates the expression of TOR2 through its 3' UTR. TOR2, as a member of the phosphatidylinositol kinase-related kinase family, plays a critical role in metabolism, development, growth, and survival at the cellular and organism levels. Recently it has been revealed that TORE2 also upregulates the molting hormone $20 \mathrm{E}$ (Cao et al., 2017). Apoptosis in Sf9 cells due to the inhibition of miR-14 indicates that it is essential for constitutive cell survival. When mimics of miR-14 precursor molecules were applied, they partially inhibited the cell death induced by actinomycin-D (Act-D). MiR-14 might have inhibitory interactions with caspases, as it functions downstream of mitochondrial cytochrome and hence averting Act-D-induced apoptosis (Kumarswamy and Chandna, 2010). Similar exploitation of hostpathogen interaction by miRNAs was also observed in other diamondback moths. Certain miRNAs are also produced by Cotesia vestalis, (a parasitoid of Plutella xylostella) and bracovirus $(\mathrm{CvBV})$. The parasitized host revealed that most of the miRNAs that arrest the host's growth were of $C$. vestalis origin. In contrast, the expression profile of the miRNAs encoded by CvBV was 100 -fold increased in parasitized hosts than non-parasitized ones. miRNAs arrest the growth of the host by modulation of the host ecdysone receptor (EcR; Wang et al., 2018).

\section{INTERACTION OF MIRNAS WITH OTHER CODING AND NON-CODING TRANSCRIPTS}

With the invention of modern techniques and a better understanding of genomic approaches, it is clear that miRNAs can have regulatory interaction with other transcripts. This complex interplay of miRNAs with these transcripts mediates the regulatory role of the different transcripts. A recent report suggests that differentially expressed long non-coding RNAs interacting with the target genes and miRNAs participate in the host response to the viral infection (BmNPV) by targeting the genes enriched ubiquitin-mediated proteolysis endocytosis and lysosome pathways in B. mori (Zhang et al., 2020).

To better understand the pathogenesis of BmCPV, the role of circular RNAs (circRNAs) acting as positive regulators in $\mathrm{BmCPV}$ infections was investigated. The researchers constructed the circRNA-miRNA interaction networks based on correlation analysis between the differentially expressed circRNAs and their miRNA binding sites. The constructed complex explained an abundant interaction between miRNAs and circ RNAs, indicating the possible role of miRNAs in association with circular RNAs (Hu et al., 2018). The circRNA circEgg encoded by B. mori histone-lysine $\mathrm{N}$-methyltransferase eggless (BmEgg) gene positively regulates histone deacetylase (HDAC) Rpd3 (BmHDAC Rpd3) gene expression by sponging the miRNA bmo-miR3,391-5p (Wang et al., 2020b; Figure 3).

In one study, miRNAs' role in host specificity was examined as miRNAs regulate the virus-host interaction. The downregulation of several genes determined the specificity. The screening of miRNA induced by AcMNPV infection combined with NGS predicts possible regulation networks indicating that these are also involved in the host specification of the virus (Chen et al., 2018). 


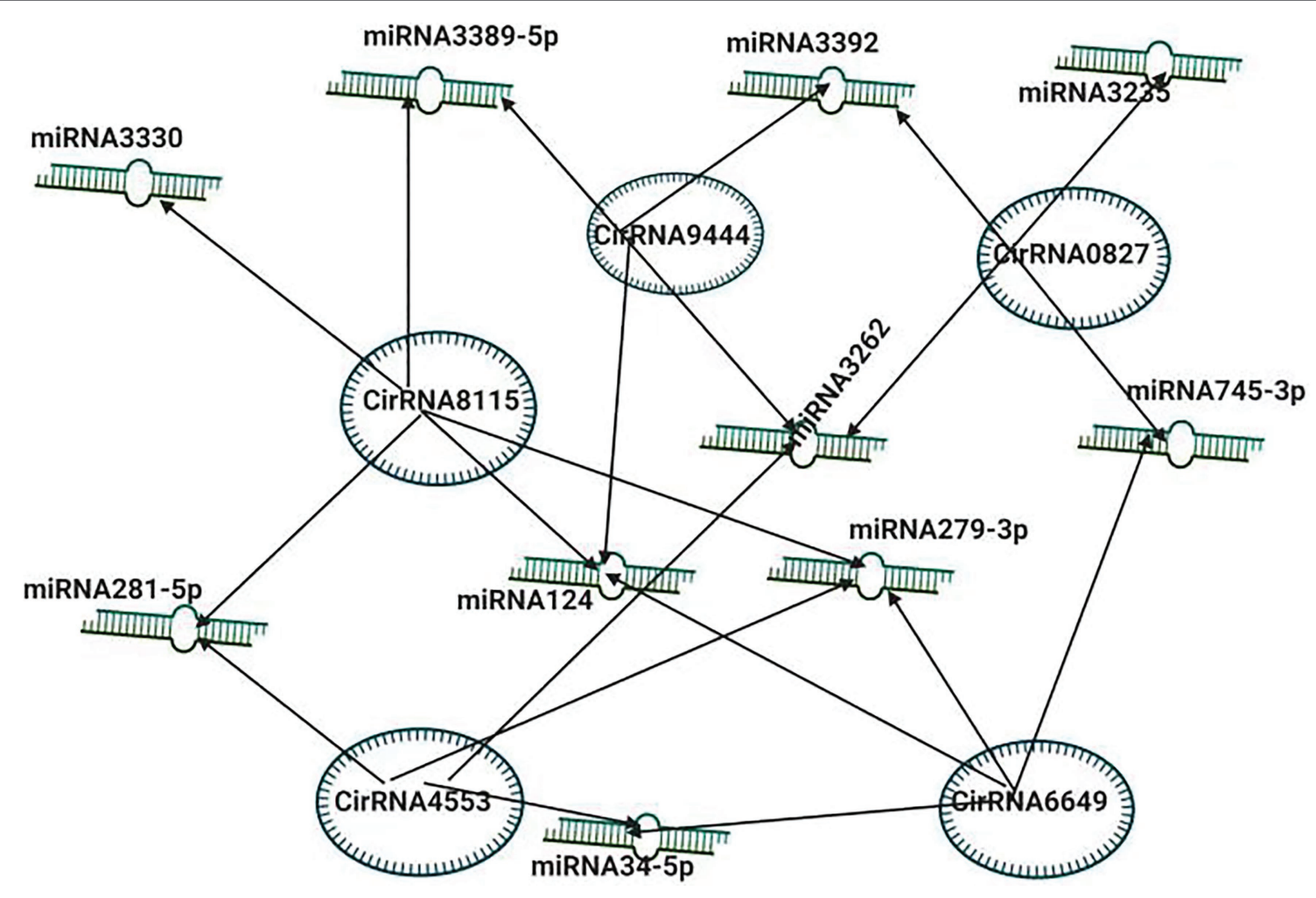

FIGURE 3 | Inter-Play between miRNA and non-coding circRNAs. The circRNA-miRNA co-expression network in silkworm. circRNAs that sponged more than four miRNAs and modulating the vital processes are shown.

\section{CONCLUSION}

With the discovery of the first miRNA nearly 30 years ago and the invention of new techniques, we have started to understand these regulatory molecules' biogenesis and diversity. The identification and characterization of miRNAs is a rapidly growing area of research. Continuing genome-wide efforts in insect miRNA discovery and expression profiling have revealed that conserved and species-specific miRNAs may play important roles in insect biology. Recently, the role of these miRNAs in host-pathogen interactions has been reported by several publications, with the majority of researchers concentrating on the impact of infection on host miRNA profile. Understanding the role of miRNAs and their targets as modulators of the insect-virus interaction can open avenues for using miRNAs, targets, and miRNA modulation pathways as a novel approach for managing viral infections and disrupting the epidemiological cycle of transmission. The hostviral interactions mediated by miRNAs provide us the basis for the use of miRNAs for insect control (Monsanto-Hearne and Johnson, 2018). Previously, similar techniques were employed by other groups when the introduction of the inverted repeatcontaining transgene was made, which in turn results in B. mori resistance to baculovirus (Sahara et al., 2003; Subbaiah et al., 2013).

MicroRNA profile of the host is generally altered upon the infection, but the amount of damage depends on the host-pathogen interaction. The host miRNA profile change might be the host response to pathogen attack, which modeled the signaling pathway and immune responses or provided aid to pathogen replication and manipulation as an optimal environment. Important regulatory roles, i.e., suppression of host anti-pathogen responses, regulation of pathogen replication, are played by the miRNAs encoded by the host to avoid the host's demise. In that context, the role of small non-coding RNAs in cross-kingdom and cell-to-cell communications in secreted forms such as exosomes opens up new windows of research. An exciting unmapped area is the involvement of miRNAs in the interaction of the gut microbiome with insects. With recent reports from mammals, it is suggested that host miRNAs might adjust the microbiota by modulating the bacterial gene transcription and hence have effects on their growth (Liu et al., 2016). It will not be surprising if similar associations exist in insects. Another remarkable aspect of miRNAs in host-pathogen interaction is their application in pest control. Zhang et al. (2014) reported the inducible and related production of amiRNAs to limit the pathogen infection in beneficial insects such as B.mori. In the same way, miRNAs may well be engaged to improve the effectiveness of biocontrol agents used against agricultural pests. In-depth investigations are required in this aspect. Several other publications also focused on the differential abundance of miRNAs. Experimental methodologies explaining the role of the differentially abundant miRNAs in host-pathogen interactions and insect immunity are of great importance. Several miRNAs encoded by viruses have also been identified, affecting virus replication by regulating or modulating the host genome facilitating their replication. These miRNAs modulate the host 
and viral transcripts during viral infection. To develop novel strategies to reduce the risk of viral infection the mechanisms of miRNA-mediated processes provide us the basis.

A given miRNA can target hundreds of different mRNAs, and on the other hand, a mRNA can be regulated by different miRNAs. This complex interplay is far from simple, and we are far from fully understanding the complex molecular mechanisms that regulate the crosstalks between baculovirus encoded miRNAs and insects. Further researches will be required to validate these scientific issues.

Additionally, the mechanisms by which cellular miRNAs are degraded after they finish their task needed to be clarified. Otherwise, they will affect cell metabolism and interfere with cellular functions. McCaskill reported RNA-mediated miRNA degradation, but it remains unclear whether the mechanism is a widespread viral strategy (McCaskill et al., 2015). Therefore, further investigations are required to answer the question.

\section{REFERENCES}

Asgari, S. (2011). Role of MicroRNAs in insect host-microorganism interactions. Front. Physiol. 2:48. doi: 10.3389/fphys.2011.00048

Bernstein, E., Caudy, A. A., Hammond, S. M., and Hannon, G. J. (2001). Role for a bidentate ribonuclease in the initiation step of RNA interference. Nature 409, 363-366. doi: 10.1038/35053110

Bogerd, H. P., Whisnant, A. W., Kennedy, E. M., Flores, O., and Cullen, B. R. (2014). Derivation and characterization of Dicer- and microRNA-deficient human cells. RNA 20, 923-937. doi: 10.1261/rna.044545.114

Bohnsack, M. T. (2004). Exportin 5 is a RanGTP-dependent dsRNA-binding protein that mediates nuclear export of pre-miRNAs. RNA 10, 185-191. doi: 10.1261/rna.5167604

Borchert, G. M., Lanier, W., and Davidson, B. L. (2006). RNA polymerase III transcribes human microRNAs. Nat. Struct. Mol. Biol. 13, 1097-1101. doi: $10.1038 / \mathrm{nsmb} 1167$

Britten, R. J., and Davidson, E. H. (1969). Gene regulation for higher cells: a theory. Science 165, 349-357. doi: 10.1126/science.165.3891.349

Burke, J. M., Kelenis, D. P., Kincaid, R. P., and Sullivan, C. S. (2014). A central role for the primary microRNA stem in guiding the position and efficiency of Drosha processing of a viral pri-miRNA. RNA 20, 1068-1077. doi: 10.1261/rna.044537.114

Cao, X., Huang, Y., Xia, D., Qiu, Z., Shen, X., Guo, X., et al. (2017). BmNPVmiR-415 up-regulates the expression of TOR2 via Bmo-miR-5738. Saudi J. Biol. Sci. 24, 1614-1619. doi: 10.1016/j.sjbs.2015.09.020

Chen, Y.-W., Wu, C.-P., Wu, T.-C., and Wu, Y.-L. (2018). Analyses of the transcriptome of Bombyx mori cells infected with either BmNPV or AcMNPV. J. Asia Pac. Entomol. 21, 37-45. doi: 10.1016/j.aspen.2017.10.009

Conrad, T., Marsico, A., Gehre, M., and Ørom, U. A. (2014). Microprocessor activity controls differential miRNA biogenesis in vivo. Cell Rep. 9, 542-554. doi: 10.1016/j.celrep.2014.09.007

Croston, T. L., Lemons, A. R., Beezhold, D. H., and Green, B. J. (2018). MicroRNA regulation of host immune responses following fungal exposure. Front. Immunol. 9:170. doi: 10.3389/fimmu.2018.00170

Czech, B., and Hannon, G. J. (2011). Small RNA sorting: matchmaking for Argonautes. Nat. Rev. Genet. 12, 19-31. doi: 10.1038/nrg2916

Czech, B., Zhou, R., Erlich, Y., Brennecke, J., Binari, R., Villalta, C., et al. (2009). Hierarchical rules for Argonaute loading in Drosophila. Mol. Cell 36, 445-456. doi: 10.1016/j.molcel.2009.09.028

Denli, A. M., Tops, B. B. J., Plasterk, R. H. A., Ketting, R. F., and Hannon, G. J. (2004). Processing of primary microRNAs by the microprocessor complex. Nature 432, 231-235. doi: 10.1038/nature03049

Farazi, T. A., Juranek, S. A., and Tuschl, T. (2008). The growing catalog of small RNAs and their association with distinct argonaute/piwi family members. Development 135, 1201-1214. doi: 10.1242/dev.005629

Feng, Y., Zhang, X., Graves, P., and Zeng, Y. (2012). A comprehensive analysis of precursor microRNA cleavage by human Dicer. RNA 18, 2083-2092. doi: $10.1261 /$ rna.033688.112

\section{AUTHOR CONTRIBUTIONS}

MA, MS, and JS drafted the manuscript. MA and MS equally contributed to the development of this manuscript. MS and JS assisted to revise the manuscript. All authors read and approved the final manuscript.

\section{FUNDING}

This study was supported by grants from the National Natural Science Foundation of China (No. 31672489, 31872426, and 32002233), Guangdong Basic and Applied Basic Research Foundation (No. 2019A1515110235), and Guangdong Provincial Promotion Project on Preservation and Utilization of Local Breed of Livestock and Poultry (No. 2018-143).

Ghildiyal, M., Xu, J., Seitz, H., Weng, Z., and Zamore, P. D. (2010). Sorting of Drosophila small silencing RNAs partitions microRNA* strands into the RNA interference pathway. RNA 16, 43-56. doi: 10.1261/rna.1972910

Ghosh, Z., Mallick, B., and Chakrabarti, J. (2009). Cellular versus viral microRNAs in host-virus interaction. Nucleic Acids Res. 37, 1035-1048. doi: 10.1093/ nar/gkn1004

Gregory, R. I., Yan, K., Amuthan, G., Chendrimada, T., Doratotaj, B., Cooch, N., et al. (2004). The microprocessor complex mediates the genesis of microRNAs. Nature 432, 235-240. doi: 10.1038/nature03120

Guo, J., Wang, Y., Chen, T., Jiang, X., Wu, P., Geng, T., et al. (2020). Functional analysis of a miRNA-like small RNA derived from Bombyx mori cytoplasmic polyhedrosis virus. Insect Sci. 27, 449-462. doi: 10.1111/1744-7917.12671

Gurtan, A. M., Lu, V., Bhutkar, A., and Sharp, P. A. (2012). In vivo structurefunction analysis of human Dicer reveals directional processing of precursor miRNAs. RNA 18, 1116-1122. doi: 10.1261/rna.032680.112

Hammond, S. M. (2001). Argonaute2, a link between genetic and biochemical analyses of RNAi. Science 293, 1146-1150. doi: 10.1126/science.1064023

Han, J. (2004). The Drosha-DGCR8 complex in primary microRNA processing. Genes Dev. 18, 3016-3027. doi: 10.1101/gad.1262504

Hu, X., Zhu, M., Zhang, X., Liu, B., Liang, Z., Huang, L., et al. (2018). Identification and characterization of circular RNAs in the silkworm midgut following Bombyx mori cytoplasmic polyhedrosis virus infection. RNA Biol. 15, 292-301. doi: 10.1080/15476286.2017.1411461

Hussain, M., and Asgari, S. (2014). MicroRNAs as mediators of insect hostpathogen interactions and immunity. J. Insect Physiol. 70, 151-158. doi: 10.1016/j.jinsphys.2014.08.003

Hutvagner, G. (2001). A cellular function for the RNA-interference enzyme dicer in the maturation of the let-7 small temporal RNA. Science 293 834-838. doi: 10.1126/science.1062961

Ishihara, G., Shimada, T., and Katsuma, S. (2013). Functional characterization of Bombyx mori nucleopolyhedrovirus CG30 protein. Virus Res. 174, 52-59. doi: 10.1016/j.virusres.2013.02.014

Jiang, F. (2005). Dicer-1 and R3D1-L catalyze microRNA maturation in Drosophila. Genes Dev. 19, 1674-1679. doi: 10.1101/gad.1334005

Jiao, Y., Wang, J., Deng, R., Yu, X., and Wang, X. (2019). AcMNPV-miR-3 is a miRNA encoded by Autographa californica nucleopolyhedrovirus and regulates the viral infection by targeting ac101. Virus Res. 267, 49-58. doi: 10.1016/j.virusres.2019.05.004

Kang, L., Wang, M., Cao, X., Tang, S., Xia, D., Shen, X., et al. (2018). Inhibition of expression of BmNPV cg30 by bmo-miRNA-390 is a host response to baculovirus invasion. Arch. Virol. 163, 2719-2725. doi: 10.1007/s00705018-3912-9

Karamipour, N., Fathipour, Y., Talebi, A. A., Asgari, S., and Mehrabadi, M. (2019). The microRNA pathway is involved in Spodoptera frugiperda (Sf9) cells antiviral immune defense against Autographa californica multiple nucleopolyhedrovirus infection. Insect Biochem. Mol. Biol. 112:103202. doi: 10.1016/j.ibmb.2019.103202 
Kawai, S., and Amano, A. (2012). BRCA1 regulates microRNA biogenesis via the DROSHA microprocessor complex. J. Cell Biol. 197, 201-208. doi: 10.1083/ jcb. 201110008

Kawamata, T., Seitz, H., and Tomari, Y. (2009). Structural determinants of miRNAs for RISC loading and slicer-independent unwinding. Nat. Struct. Mol. Biol. 16, 953-960. doi: 10.1038/nsmb.1630

Kim, V. N. (2008). Sorting out small RNAs. Cell 133, 25-26. doi: 10.1016/j. cell.2008.03.015

Kim, Y.-K., Kim, B., and Kim, V. N. (2016). Re-evaluation of the roles of DROSHA, Exportin 5, and DICER in microRNA biogenesis. Proc. Natl. Acad. Sci. U. S. A. 113, E1881-E1889. doi: 10.1073/pnas.1602532113

Kolliopoulou, A., and Swevers, L. (2013). Functional analysis of the RNAi response in ovary-derived silkmoth Bm5 cells. Insect Biochem. Mol. Biol. 43, 654-663. doi: 10.1016/j.ibmb.2013.05.001

Kolliopoulou, A., Van Nieuwerburgh, F., Stravopodis, D. J., Deforce, D., Swevers, L., and Smagghe, G. (2015). Transcriptome analysis of Bombyx mori larval midgut during persistent and pathogenic cytoplasmic Polyhedrosis virus infection. PLoS One 10:e0121447. doi: 10.1371/journal.pone.0121447

Koscianska, E., Starega-Roslan, J., and Krzyzosiak, W. J. (2011). The role of dicer protein partners in the processing of MicroRNA precursors. PLoS One 6:e28548. doi: 10.1371/journal.pone.0028548

Kozomara, A., Birgaoanu, M., and Griffiths-Jones, S. (2019). miRBase: from microRNA sequences to function. Nucleic Acids Res. 47, D155-D162. doi: 10.1093/nar/gky1141

Kumarswamy, R., and Chandna, S. (2010). Inhibition of microRNA-14 contributes to actinomycin-D-induced apoptosis in the Sf9 insect cell line. Cell Biol. Int. 34, 851-857. doi: 10.1042/CBI20100035

Landthaler, M., Yalcin, A., and Tuschl, T. (2004). The human DiGeorge syndrome critical region gene 8 and its $D$. melanogaster homolog are required for miRNA biogenesis. Curr. Biol. 14, 2162-2167. doi: 10.1016/j.cub.2004.11.001

Lee, Y., Ahn, C., Han, J., Choi, H., Kim, J., Yim, J., et al. (2003). The nuclear RNase III Drosha initiates microRNA processing. Nature 425, 415-419. doi: 10.1038/nature01957

Lee, R. C., Feinbaum, R. L., and Ambros, V. (1993). The C. elegans heterochronic gene lin-4 encodes small RNAs with antisense complementarity to lin-14. Cell 75, 843-854. doi: 10.1016/0092-8674(93)90529-Y

Lee, Y., Kim, M., Han, J., Yeom, K.-H., Lee, S., Baek, S. H., et al. (2004). MicroRNA genes are transcribed by RNA polymerase II. EMBO J. 23, 4051-4060. doi: 10.1038/sj.emboj.7600385

Liu, S., da Cunha, A. P., Rezende, R. M., Cialic, R., Wei, Z., Bry, L., et al. (2016). The host shapes the gut microbiota via Fecal MicroRNA. Cell Host Microbe 19, 32-43. doi: 10.1016/j.chom.2015.12.005

Lund, E. (2004). Nuclear export of MicroRNA precursors. Science 303, 95-98. doi: $10.1126 /$ science.1090599

Maudet, C., Mano, M., and Eulalio, A. (2014). MicroRNAs in the interaction between host and bacterial pathogens. FEBS Lett. 588, 4140-4147. doi: 10.1016/j.febslet.2014.08.002

McCaskill, J., Praihirunkit, P., Sharp, P. M., and Buck, A. H. (2015). RNAmediated degradation of microRNAs: a widespread viral strategy? RNA Biol. 12, 579-585. doi: 10.1080/15476286.2015.1034912

Miyoshi, K., Okada, T. N., Siomi, H., and Siomi, M. C. (2009). Characterization of the miRNA-RISC loading complex and miRNA-RISC formed in the Drosophila miRNA pathway. RNA 15, 1282-1291. doi: 10.1261/rna.1541209

Moazed, D. (2009). Small RNAs in transcriptional gene silencing and genome defence. Nature 457, 413-420. doi: 10.1038/nature07756

Monsanto-Hearne, V., and Johnson, K. N. (2018). miRNAs in insects infected by animal and plant viruses. Viruses 10:354. doi: 10.3390/v10070354

Nguyen, T. A., Jo, M. H., Choi, Y.-G., Park, J., Kwon, S. C., Hohng, S., et al. (2015). Functional anatomy of the human microprocessor. Cell 161, 1374-1387. doi: 10.1016/j.cell.2015.05.010

Okamura, K., Liu, N., and Lai, E. C. (2009). Distinct mechanisms for microRNA strand selection by Drosophila Argonautes. Mol. Cell 36, 431-444. doi: 10.1016/j.molcel.2009.09.027

Pan, Z.-H., Wu, P., Gao, K., Hou, C.-X., Qin, G.-X., Geng, T., et al. (2017). Identification and characterization of two putative microRNAs encoded by Bombyx mori cypovirus. Virus Res. 233, 86-94. doi: 10.1016/j.virusres.2017.03.009

Ponnuvel, K. M., Sundari, B. M., Kumar, R. S., Sinha, R. K., and Kamble, C. K. (2007). Identification of a putative RNAse III (dicer homolog) gene in silkworm Bombyx mori. Invertebr. Surviv. J. 4, 18-23.
Ran, Z., Shi, X., Han, F., Li, J., Zhang, Y., Zhou, Y., et al. (2018). Expressing MicroRNA bantam sponge drastically improves the insecticidal activity of baculovirus via increasing the level of ecdysteroid hormone in Spodoptera exigua larvae. Front. Microbiol. 9:1824. doi: 10.3389/fmicb.2018.01824

Reinhart, B. J., Slack, F. J., Basson, M., Pasquinelli, A. E., Bettinger, J. C., Rougvie, A. E., et al. (2000). The 21-nucleotide let-7 RNA regulates developmental timing in Caenorhabditis elegans. Nature 403, 901-906. doi: $10.1038 / 35002607$

Riddiford, L. M., Hiruma, K., Zhou, X., and Nelson, C. A. (2003). Insights into the molecular basis of the hormonal control of molting and metamorphosis from Manduca sexta and Drosophila melanogaster. Insect Biochem. Mol. Biol. 33, 1327-1338. doi: 10.1016/j.ibmb.2003.06.001

Sahara, K., Asano, S.-I., Bando, H., Isobe, R., Kojima, K., Matsuyama, T., et al. (2003). Use of RNAi technology to confer enhanced resistance to BmNPV on transgenic silkworms. Arch. Virol. 149, 1931-1940. doi: 10.1007/ s00705-004-0349-0

Saito, K., Ishizuka, A., Siomi, H., and Siomi, M. C. (2005). Processing of premicroRNAs by the Dicer-1-loquacious complex in Drosophila cells. PLoS Biol. 3:e235. doi: 10.1371/journal.pbio.0030235

Santos, D., Mingels, L., Vogel, E., Wang, L., Christiaens, O., Cappelle, K., et al. (2019). Generation of virus- and dsRNA-derived siRNAs with speciesdependent length in insects. Viruses 11:738. doi: 10.3390/v11080738

Shi, X., Ran, Z., Li, S., Yin, J., and Zhong, J. (2016). The effect of MicroRNA bantam on baculovirus AcMNPV infection in vitro and in vivo. Viruses 8:136. doi: $10.3390 / \mathrm{v} 8050136$

Singh, C. P., Singh, J., and Nagaraju, J. (2012). A baculovirus-encoded MicroRNA (miRNA) suppresses its host miRNA biogenesis by regulating the Exportin-5 cofactor Ran. J. Virol. 86, 7867-7879. doi: 10.1128/JVI.00064-12

Singh, C. P., Singh, J., and Nagaraju, J. (2014). Bmnpv-miR-3 facilitates BmNPV infection by modulating the expression of viral P6.9 and other late genes in Bombyx mori. Insect Biochem. Mol. Biol. 49, 59-69. doi: 10.1016/j. ibmb.2014.03.008

Siomi, M. C., Sato, K., Pezic, D., and Aravin, A. A. (2011). PIWI-interacting small RNAs: the vanguard of genome defence. Nat. Rev. Mol. Cell Biol. 12, 246-258. doi: 10.1038/nrm3089

Skalsky, R. L., and Cullen, B. R. (2010). Viruses, microRNAs, and host interactions. Annu. Rev. Microbiol. 64, 123-141. doi: 10.1146/annurev.micro.112408.134243

Subbaiah, E. V., Royer, C., Kanginakudru, S., Satyavathi, V. V., Babu, A. S., Sivaprasad, V., et al. (2013). Engineering silkworms for resistance to baculovirus through multigene RNA interference. Genetics 193, 63-75. doi: 10.1534/ genetics.112.144402

Tang, Q., Qiu, L., and Li, G. (2019). Baculovirus-encoded MicroRNAs: a brief overview and future prospects. Curr. Microbiol. 76, 738-743. doi: 10.1007/ s00284-018-1443-y

Wang, G.-H., Jiang, L., Zhu, L., Cheng, T.-C., Niu, W.-H., Yan, Y.-F., et al. (2013). Characterization of Argonaute family members in the silkworm, Bombyx mori: Argonaute family members in Bombyx mori. Insect Sci. 20, 78-91. doi: 10.1111/j.1744-7917.2012.01555.x

Wang, J., Xing, K., Xiong, P., Liang, H., Zhu, M., Huang, S., et al. (2020a). Characterization of miRNAs encoded by Autographa californica nucleopolyhedrovirus. Microbiology [Preprint]. doi: 10.1101/2020.05.13.094193

Wang, Z., Ye, X., Shi, M., Li, F., Wang, Z., Zhou, Y., et al. (2018). Parasitic insect-derived miRNAs modulate host development. Nat. Commun. 9:2205. doi: 10.1038/s41467-018-04504-1

Wang, Z., Zhang, Y., Dai, K., Liang, Z., Zhu, M., Zhang, M., et al. (2020b). circEgg regulates histone $\mathrm{H} 3 \mathrm{~K} 9 \mathrm{me} 3$ by sponging bmo-miR-3391-5p and encoding circEgg-P122 protein in the silkworm, Bombyx mori. Insect Biochem. Mol. Biol. 124:103430. doi: 10.1016/j.ibmb.2020.103430

Wightman, B., Ha, I., and Ruvkun, G. (1993). Posttranscriptional regulation of the heterochronic gene lin-14 by lin- 4 mediates temporal pattern formation in C. elegans. Cell 75, 855-862. doi: 10.1016/0092-8674(93)90530-4

Wu, P., Han, S., Chen, T., Qin, G., Li, L., and Guo, X. (2013). Involvement of MicroRNAs in infection of silkworm with Bombyx mori cytoplasmic Polyhedrosis virus (BmCPV). PLoS One 8:e68209. doi: 10.1371/journal. pone.0068209

Wu, P., Jiang, X., Sang, Q., Annan, E., Cheng, T., and Guo, X. (2017). Inhibition of miR-274-3p increases BmCPV replication by regulating the expression of BmCPV NS5 gene in Bombyx mori. Virus Genes 53, 643-649. doi: 10.1007/ s11262-017-1466-7 
Wu, P., Qin, G., Qian, H., Chen, T., and Guo, X. (2016). Roles of miR-278-3p in IBP2 regulation and Bombyx mori cytoplasmic polyhedrosis virus replication. Gene 575, 264-269. doi: 10.1016/j.gene.2015.09.009

Wu, P., Shang, Q., Dweteh, O. A., Huang, H., Zhang, S., Zhong, J., et al. (2019). Over expression of bmo-miR-2819 suppresses BmNPV replication by regulating the BmNPV ie-1 gene in Bombyx mori. Mol. Immunol. 109, 134-139. doi: 10.1016/j.molimm.2019.03.013

Yi, R. (2003). Exportin-5 mediates the nuclear export of pre-microRNAs and short hairpin RNAs. Genes Dev. 17, 3011-3016. doi: 10.1101/gad.1158803

Ylla, G., Fromm, B., Piulachs, M.-D., and Belles, X. (2016). The microRNA toolkit of insects. Sci. Rep. 6:37736. doi: 10.1038/srep37736

Zhang, J., He, Q., Zhang, C.-D., Chen, X.-Y., Chen, X.-M., Dong, Z.-Q., et al. (2014). Inhibition of BmNPV replication in silkworm cells using inducible and regulated artificial microRNA precursors targeting the essential viral gene lef-11. Antivir. Res. 104, 143-152. doi: 10.1016/j.antiviral.2014.01.017

Zhang, S., Yin, H., Shen, M., Huang, H., Hou, Q., Zhang, Z., et al. (2020). Analysis of IncRNA-mediated gene regulatory network of Bombyx mori in response to BmNPV infection. J. Invertebr. Pathol. 170:107323. doi: 10.1016/j. jip.2020.107323
Zhu, M., Wang, J., Deng, R., and Wang, X. (2016). Functional regulation of an Autographa californica nucleopolyhedrovirus-encoded MicroRNA, AcMNPVmiR-1, in baculovirus replication. J. Virol. 90, 6526-6537. doi: 10.1128/ JVI.00165-16

Zografidis, A., Van Nieuwerburgh, F., Kolliopoulou, A., Apostolou-Karampelis, K., Head, S. R., Deforce, D., et al. (2015). Viral small-RNA analysis of Bombyx mori larval midgut during persistent and pathogenic cytoplasmic Polyhedrosis virus infection. J. Virol. 89, 11473-11486. doi: 10.1128/JVI.01695-15

Conflict of Interest: The authors declare that the research was conducted in the absence of any commercial or financial relationships that could be construed as a potential conflict of interest.

Copyright $\odot 2021$ Awais, Shakeel and Sun. This is an open-access article distributed under the terms of the Creative Commons Attribution License (CC BY). The use, distribution or reproduction in other forums is permitted, provided the original author(s) and the copyright owner(s) are credited and that the original publication in this journal is cited, in accordance with accepted academic practice. No use, distribution or reproduction is permitted which does not comply with these terms. 